\title{
Abscisic Acid Increases Carotenoid and Chlorophyll Concentrations in Leaves and Fruit of Two Tomato Genotypes
}

\author{
T. Casey Barickman', Dean A. Kopsell ${ }^{2}$, and Carl E. Sams ${ }^{2,3}$ \\ Plant Sciences Department, The University of Tennessee, Room 252 Plant Sciences Building, 2431 Joe \\ Johnson Drive, Knoxville, TN 37996
}

\begin{abstract}
Additional Index words. $\beta$-carotene, chlorophyll, lutein, lycopene, xanthophyll
Abstract. One important regulator that coordinates response to environmental stress is the hormone abscisic acid (ABA), which is synthesized from xanthophyll pigments. Despite the fact that there is strong evidence of increases in ABA concentrations under various environmental stresses, information concerning the effects of exogenous $A B A$ applications on leaf pigments and fruit carotenoids in tomato (Solanum lycopersicum) is lacking. This study investigated the impacts of root tissue $\mathrm{ABA}$ applications on tomato leaf and fruit pigmentation concentrations of 'MicroTina' and 'MicroGold' tomato plants. Tomato plants were treated with increasing concentrations of ABA in the nutrient solution. Therefore, the purpose of this study was to determine dose-response effects of ABA treatment in solution culture for maximum leaf pigmentation and fruit carotenoids in two distinct genotypes of dwarf tomato. Because ABA is a product of the carotenoid biosynthetic pathway, we hypothesized that applications of ABA treatments would have a positive impact on leaf chlorophylls and carotenoids. Applications of ABA treatments may also have a positive impact on tomato fruit carotenoids. The results indicated that 'MicroTina' plants treated with ABA $\left(0.5,5.0\right.$, and $\left.10.0 \mathrm{mg} \cdot \mathrm{L}^{-1}\right)$ had a significant increase in $\beta$-carotene $[B C(P \leq 0.001)]$, lutein $[\mathrm{LUT}(P \leq 0.001)]$, zeaxanthin [ZEA $(P \leq 0.05)]$, and neoxanthin [NEO $(P \leq 0.001)]$ in the leaf tissue. In 'MicroGold' tomato plants, carotenoids responded similarly. For example, there were significant increases in BC $(P \leq 0.01)$, LUT $(P \leq 0.001), Z E A$ $(P \leq 0.05)$, and NEO $(P \leq 0.001)$. In 'MicroTina' tomato leaves, there were significant increases in chlorophyll $a$ [Chl $a(P \leq 0.001)]$ and chlorophyll $b[\mathrm{Chl} b(P \leq 0.001)]$ concentrations. Furthermore, there were significant increases in $\mathrm{Chl} a(P \leq 0.001)$ and $\mathrm{Chl} b(P \leq 0.001)$ in 'MicroGold' leaf tissue. In 'MicroTina' tomato fruit tissue, the concentration increased significantly for lycopene $[\mathrm{LYCO}(P \leq 0.01)]$. However, in 'MicroGold', there were no significant changes in BC and LUT concentrations. In addition, LYCO was found to be below detection limits in 'MicroGold' tomato fruit. Therefore, ABA has been shown to positively change tomato leaf pigments in both genotypes and fruit tissue carotenoid concentrations in 'MicroTina' tomato.
\end{abstract}

Plant responses to environmental stress involve a number of metabolic and physiological changes. One important regulator that coordinates response to environmental stress is the hormone, ABA, which is synthesized from xanthophyll pigments (Taylor et al., 1988). Concentrations of ABA increase in plant tissues in response to environmental stress resulting in drought-induced stomatal closure (Desikan et al., 2004), accumulation of secondary messenger molecules (Wang et al., 2012), and enhancement of ABA-responsive gene expression (Liu et al., 2010). One of the most important abiotic stress factors, water deficit, can regulate plant growth and development, thus limiting plant production (Jiang and Zhang, 2002). However, plants will produce ABA in low levels in the absence of stress factors. Therefore, ABA is an important component in the mechanisms of resistance and adaptation to abiotic stress conditions (Berli et al., 2010).

The role of ABA in protecting the xanthophyll cycle (deepoxidation of violaxanthin to zeaxanthin through antheraxanthin) and the photosynthetic apparatus from photo-oxidative stress is well documented (Du et al., 2010). For example, exogenous applications of ABA to barley (Hordeum vulgar)

Received for publication 26 Aug. 2013. Accepted for publication 10 Feb. 2014. This research was made possible through support from the University of Tennessee Institute of Agriculture.

${ }^{1}$ Research Associate/Graduate Research Assistant.

${ }^{2}$ Professor.

${ }^{3}$ Corresponding author. E-mail: carlsams@utk.edu. seedlings resulted in an increase in total and xanthophyll carotenoid concentrations by $122 \%$ protecting photosystem II (PSII) against photoinhibition at low temperatures (Ivanov et al., 1995). Haisel et al. (2006) found that seedlings of bean (Phaseolus vulgaris), tobacco (Nicotiana tabacum), beet (Beta vulgaris), and corn (Zea mays) pre-treated with ABA demonstrated increased chlorophyll and carotenoid concentrations under water stress. Sorghum (Sorghum bicolor) seedlings supplemented with ABA and exposed to light intensities to induce photo-inhibition (2200 and $3600 \mu \mathrm{mol} \cdot \mathrm{m}^{-2} \cdot \mathrm{s}^{-1}$ photosynthetically active radiation) had better energy dissipation and much greater levels of de-epoxidation than control seedlings (Sharma et al., 2002). In addition, ABA plays an important role during fruit ripening. Research has indicated that ABAassociated genes were highly expressed in ripening fruit (Zhang et al., 2009) and that application of ABA accelerated ethylene biosynthesis, therefore regulating fruit ripening (Zaharah et al., 2013). The de novo synthesis of carotenoids in the tomato fruit tissue, mainly lycopene and $\beta$-carotene, are associated with the color changes from green to red as chloroplasts are transformed to chromoplasts (Pék et al., 2010). Thus, the change in color may be the result of ABA-induced accelerated ethylene biosynthesis in the tomato fruit. Furthermore, foliar-applied ABA on grapes (Vitis vinifera) resulted in stimulatory effects on fruit color (Cantin et al., 2007).

Despite the fact that there is strong evidence of increases in ABA concentrations under various environmental stresses, 
information regarding the effects of exogenous ABA applications on leaf pigments and fruit carotenoids in tomato is lacking. Tomato seedlings are grown in greenhouses under controlled conditions in seedling cultivation operations. However, when transplanted into the field, tomato plants are exposed to a wide range of environmental conditions that can be detrimental to growth and development. Furthermore, although the tomato plants are exposed to these adverse conditions, consumers want tomato fruit that are more nutritious. Adverse environmental conditions such as drought, excess light, and high-temperature stress may negatively affect the nutritional values of tomato fruit. Among carotenoids, LYCO is one of the most potent antioxidants and is a major component of red tomato fruit (Miller et al., 1996). Research has indicated that LYCO is a powerful antioxidant that can prevent cancers. For example, Tang et al. (2005) demonstrated that naturally occurring LYCO doses of 100 to $300 \mathrm{mg} \cdot \mathrm{kg}^{-1}$ inhibited cancerous prostrate cells in mice by more than $50 \%$. Therefore, the purpose of this study was to determine dose-response effects of ABA treatment in solution culture for maximum leaf pigmentation and fruit carotenoids in two distinct genotypes of dwarf tomato. Dwarf tomato plants were chosen for their genetic homology to large tomato plants and small size for benchtop experimentation. Because ABA is a product of the carotenoid biosynthetic pathway, we hypothesized that applications of ABA treatments would have a positive impact on leaf chlorophylls and carotenoids. Therefore, applications of ABA treatments may also have a positive impact on tomato fruit carotenoids.

\section{Materials and Methods}

Plant Culture and harvest. Seeds of 'MicroTina' and 'MicroGold' tomato (provided by Dr. Jay Scott, The University of Florida) were sown into $2.5 \times 2.5-\mathrm{cm}$ growing cubes (Grodan, Hedehusene, Denmark), germinated under greenhouse conditions, and grown at $25 / 20{ }^{\circ} \mathrm{C}$ (day/night). Natural photoperiod and intensity of sunlight for tomato production in the greenhouse were supplemented with 24 individual 1000-W high-pressure sodium lights under a 16 -h photoperiod. The lights delivered an average of $850 \mu \mathrm{mol} \cdot \mathrm{m}^{-2} \cdot \mathrm{s}^{-1}$ over the entire photoperiod. Light intensity readings were taken $1.22 \mathrm{~m}$ off the ground (just above the tomato canopy). At $21 \mathrm{~d}$ after seeding, the plantlets were transferred to $11-\mathrm{L}$ containers (Rubbermaid, Wooster, $\mathrm{OH}$ ) filled with $10 \mathrm{~L}$ of nutrient solution. Tomato plants were grown hydroponically with a tomato fertilizer scheme developed at the University of Tennessee. Elemental concentrations of the nutrient solutions were $\left(\mathrm{mg} \cdot \mathrm{L}^{-1}\right)$ : nitrogen (180), phosphorus (93.0), potassium (203.3), calcium (180), magnesium (48.6), sulfur (96.3), iron (1.0), boron (0.25), manganese $(0.25)$, zinc $(0.025)$, copper $(0.01)$, and molybdenum (0.005). The two genotypes were grown in separate experiments with an experimental design consisting of a randomized complete block with four replications. Each reservoir contained two plants with individual reservoirs representing an experimental unit. Treatments consisted of ABA (s-ABA; Valent BioSciences, Libertyville, IL) applied to nutrient solutions at concentrations of $0.0,0.5,5.0$, and $10.0 \mathrm{mg} \cdot \mathrm{L}^{-1}$. Solutions were aerated with an air blower (Model 25E133W222; Spencer, Winsor, CT) connected to air stones in each reservoir. Complete nutrient solution and treatment changes were made every week until study conclusion. Fruit tissues were harvested 84 to $90 \mathrm{~d}$ after seeding. Ten ripe fruit for each experimental unit were juiced and prepared for carotenoid analysis. Harvested fruit samples were stored at $-20{ }^{\circ} \mathrm{C}$ for no longer than $14 \mathrm{~d}$ before analysis. Leaf samples were taken on last harvest and were frozen at $-80{ }^{\circ} \mathrm{C}$ until analysis for chlorophylls and carotenoids.

Fruit carotenoid tissue analysis. Carotenoids were extracted from fresh-frozen ripe fruit tissues and quantified according to the methods of Emenhiser et al. (1996) with slight modifications. Fruit was removed from $-20^{\circ} \mathrm{C}$ and thawed until slightly pliable. A sample of 10 whole ripe fruits from each experimental unit (treatment) was blended into a slurry. A 2.0-g subsample of the slurry was placed into a test tube $(20 \times 150 \mathrm{~mm})$, and $5 \mathrm{~mL}$ of hexane and $0.8 \mathrm{~mL}$ of the internal standard (ethyl$\beta$ - $8^{\prime}$-apo-carotenoate; CaroteNature, Lupsingen, Switzerland) were added. Test tubes were vortexed for $1 \mathrm{~min}$ before addition of $5 \mathrm{~mL}$ of tetrahydrofuran and then vortexed for $1 \mathrm{~min}$ before additions of $5 \mathrm{~mL}$ of reverse osmosis water. After vortexing for $20 \mathrm{~s}$, test tubes were stored at $4{ }^{\circ} \mathrm{C}$ for $10 \mathrm{~min}$ to achieve aqueous-organic separations. Tubes were then centrifuged at $500 \mathrm{~g}_{\mathrm{n}}$ for $10 \mathrm{~min}$. The organic top layer was removed using a disposable Pasteur pipette and placed into a graduated conical test tube. The sample volume was reduced to dryness under a stream of nitrogen gas (N-EVAP 111; Organomation, Berlin, MA). Samples were brought up to a final volume of $5 \mathrm{~mL}$ with acetone, and a $2-\mathrm{mL}$ aliquot was filtered through a $0.2-\mu \mathrm{m}$ polytetrafluoroethylene (PTFE) filter (Econofilter PTFE 25/20; Agilent Technologies, Santa Clara, CA) before high-performance liquid chromatography (HPLC) analysis.

A HPLC unit with a photodiode array detector (1200 series; Agilent Technologies) was used for pigment separation. Chromatographic separations were achieved using an analytical scale $(250 \times 4.6 \mathrm{~mm}$ i.d. $) 5-\mu \mathrm{m}$ polymeric $\mathrm{RP}^{-\mathrm{C}_{30}}$ column (ProntoSIL; MAC-MOD Analytical, Chadds Ford, PA), which allowed for effective separation of chemically similar pigment compounds. The column was equipped with a $5-\mu m$ guard cartridge $(10 \times 4.0 \mathrm{~mm}$ i.d. $)$ and holder (ProntoSIL) and was maintained at $40{ }^{\circ} \mathrm{C}$ using a thermostatted column compartment. All separations were achieved isocratically using a binary mobile phase of $38.00 \%$ methyl tert-butyl ether, $61.99 \%$ methanol, and $0.01 \%$ triethylamine $(\mathrm{v} / \mathrm{v} / \mathrm{v})$. The flow rate was $1.0 \mathrm{~mL} \cdot \mathrm{min}^{-1}$ with a run time of $40 \mathrm{~min}$. Eluted compounds from a $10-\mu \mathrm{L}$ injection loop were detected at $453 \mathrm{~nm}$; and data were collected, recorded, and integrated using ChemStation Software Version B.01.01 (Agilent Technologies). Peak assignment for individual pigments was performed by comparing retention times and line spectra obtained from photodiode array detection using external standards of BC, LUT, and LYCO (ChromaDex, Irvine, CA).

LEAF CAROTENOID AND CHLOROPHYLL ANALYSIS. The frozen tomato leaf samples were lyophilized in a programmed freeze dryer (Model 6L FreeZone; LabConCo, Kansas City, MO). Freeze-dried tissues were then ground in liquid nitrogen with a mortar and pestle. Pigments were extracted and separated according to Kopsell et al. (2004), which was based on the method of Khachik et al. (1986). HPLC separation parameters and pigment quantification followed procedures of Kopsell et al. (2007). A HPLC unit with a photodiode array detector (1200 series; Agilent Technologies) was used for pigment separation.

Statistical anAlysis. Data were analyzed using the PROC Mixed Model analysis of variance (ANOVA) procedure of SAS (Version 9.3; SAS Institute, Cary, NC) (Garcia-Mina et al., 2013). The fixed effect for the experiment consisted of the control $\left(0.0 \mathrm{mg} \cdot \mathrm{L}^{-1} \mathrm{ABA}\right)$ and ABA treatments $(0.5,5.0$, and 
$\left.10.0 \mathrm{mg} \cdot \mathrm{L}^{-1}\right)$, whereas replications were analyzed as random effects. The mean differences among the ABA treatments $(0.5$, 5.0 , and $10.0 \mathrm{mg} \cdot \mathrm{L}^{-1}$ ) were not significant. Therefore, a one-way ANOVA contrast was conducted to compare the mean differences between the control treatment and the combined ABA treatments. The SES are based on the pooled error term from the ANOVA table. We report model-based values rather than unequal SE from a databased calculation because pooled errors reflect the statistical testing being done. We conducted diagnostic tests to ensure that treatment variances were statistically equal before pooling.

\section{Results}

IMPACT OF ABA ON TOMATO LEAF CAROTENOIDS AND CHLOROPHYLLS. The mean separation of the ABA treatments $\left(0.5,5.0\right.$, and $\left.10.0 \mathrm{mg} \cdot \mathrm{L}^{-1}\right)$ was not significant. Therefore, the ABA treatments were pooled and compared with the control treatment. The application of ABA treatments to the nutrient solution increased the accumulation of BC (49.1\%), LUT $(32.3 \%)$, ZEA $(64.9 \%)$, and NEO $(31.4 \%)$ carotenoids in 'MicroTina' tomato leaf tissue when compared with the control treatment (Table 1). In 'MicroGold' tomato, leaf tissue carotenoids responded similarly when treated with ABA compared with the control (Table 2). BC increased $42.3 \%$ in the ABA-treated leaf tissue. LUT increased $25.1 \%$ in ABA-treated leaf tissue. ZEA increased $35.7 \%$ in ABA-treated leaf tissue. NEO increased $30.8 \%$ in the leaf tissue of ABA-treated tomato plants.

In both genotypes, total carotenoids increased in plant treated with $\mathrm{ABA}$ in the nutrient solution when compared with the control. Total carotenoids increased significantly in 'MicroTina' tomato leaves (Table 1). Leaves of 'MicroGold' had an increase in total carotenoids in treated tomato plants (Table 2). Similarly, total leaf tissue chlorophyll pigments increased in both 'MicroTina' and 'MicroGold' tomato plants. Specifically, Chl $a$ increased 40.4\%, whereas Chl $b$ increased $27.0 \%$ in 'MicroTina' treated tomato plants (Table 3). Additionally, Chl $a$ and $\mathrm{Chl} b$ in 'MicroGold' tomato leaves increased by $39.0 \%$ and $24.9 \%$, respectively (Table 4 ). Therefore, the results indicate that $\mathrm{ABA}$ treatment applications increase carotenoid

Table 1. Mean values for carotenoids leaf tissue pigment in non-treated and abscisic acid (ABA) treated 'MicroTina' tomato plants grown in hydroponic nutrient solution. ${ }^{\mathrm{z}}$

\begin{tabular}{lccccccc}
\hline \multicolumn{7}{c}{ Mean carotenoid concn $(\mathrm{mg} / 100 \mathrm{~g} \text { fresh wt) })^{\mathrm{y}}$} \\
\hline $\begin{array}{l}\text { ABA } \\
\left(\mathrm{mg} \cdot \mathrm{L}^{-1}\right)\end{array}$ & BC & LUT & ZEA & ANTH & NEO & VIO & CAR \\
\hline 0.0 & 3.33 & 10.95 & 0.20 & 1.61 & 4.28 & 1.36 & 20.52 \\
0.5 & 6.18 & 15.43 & 0.35 & 1.72 & 6.17 & 1.82 & 30.15 \\
5.0 & 6.79 & 16.68 & 0.63 & 1.90 & 6.36 & 1.31 & 31.82 \\
10.0 & 6.65 & 16.46 & 0.72 & 1.91 & 6.20 & 1.62 & 31.29 \\
Contrast & & & & & & & \\
Control vs. & $*$ & $* *$ & $* *$ & NS & $*$ & NS & $* *$ \\
$\quad$ ABA & & & & & & &
\end{tabular}

\footnotetext{
${ }^{\mathrm{z}}$ Mean separation of the ABA treatments were not significant; therefore, ABA treatments were pooled for statistical analysis.

${ }^{\mathrm{y}} \mathrm{BC}=\beta$-carotene; LUT $=$ lutein; $\mathrm{ZEA}=$ zeaxanthin; $\mathrm{ANTH}=$ antheroxanthin; $\mathrm{NEO}=$ neoxanthin; $\mathrm{VIO}=$ violaxanthin; Total $\mathrm{CAR}=$ total carotenoids. SE was $\mathrm{BC} \pm 0.65, \mathrm{LUT} \pm 0.84, \mathrm{ZEA} \pm 0.12, \mathrm{ANTH} \pm$ $0.24, \mathrm{NEO} \pm 0.44, \mathrm{VIO} \pm 0.44$, Total $\mathrm{CAR} \pm 1.92$.

${ }^{\mathrm{N}_{\mathrm{NS}},{ }^{*} \text {, and }}{ }^{* *}$ indicate nonsignificant or significant at $P \leq 0.05$ and 0.01 , respectively.
}

Table 2. Mean values for carotenoids leaf tissue pigment in non-treated and abscisic acid (ABA) treated 'MicroGold' tomato plants grown in hydroponic nutrient solution. ${ }^{\mathrm{z}}$

\begin{tabular}{lccccccc}
\hline \multicolumn{7}{c}{ Mean carotenoid concn $\left(\mathrm{mg} / 100 \mathrm{~g}_{\text {fresh wt }}\right)^{\mathrm{y}}$} \\
\hline $\begin{array}{l}\text { ABA } \\
\left(\mathrm{mg} \cdot \mathrm{L}^{-1}\right)\end{array}$ & BC & LUT & ZEA & ANTH & NEO & VIO & CAR \\
\hline 0.0 & 3.23 & 11.02 & 0.27 & 1.39 & 3.98 & 1.02 & 20.54 \\
0.5 & 5.59 & 14.54 & 0.36 & 1.98 & 5.64 & 1.52 & 29.43 \\
5.0 & 5.93 & 14.92 & 0.45 & 2.13 & 5.74 & 1.43 & 30.13 \\
10.0 & 5.26 & 14.68 & 0.46 & 1.90 & 5.88 & 1.36 & 29.00 \\
Contrast & & & & & & & \\
$\begin{array}{l}\text { Control vs. } \\
\quad \text { NS }\end{array}$ & $* *$ & $*$ & NS & $* *$ & NS & $* *$ \\
\hline
\end{tabular}

${ }^{\mathrm{z}}$ Mean separation of the ABA treatments were not significant; therefore, $\mathrm{ABA}$ treatments were pooled for statistical analysis.

${ }^{\mathrm{y}} \mathrm{BC}=\beta$-carotene; LUT $=$ lutein; $\mathrm{ZEA}=$ zeaxanthin; $\mathrm{ANTH}=$ antheroxanthin; $\mathrm{NEO}=$ neoxanthin; $\mathrm{VIO}=$ violaxanthin; Total $\mathrm{CAR}=$ total carotenoids. SE was $\mathrm{BC} \pm 0.61, \mathrm{LUT} \pm 0.61, \mathrm{ZEA} \pm 0.08, \mathrm{ANTH} \pm$ $0.27, \mathrm{NEO} \pm 0.31, \mathrm{VIO} \pm 0.21$, Total $\mathrm{CAR} \pm 1.44$.

${ }_{\mathrm{NS}}^{\mathrm{NS}}{ }^{*}$, and $* *$ indicate nonsignificant or significant at $P \leq 0.05$ and 0.01 , respectively.

Table 3. Mean values for chlorophyll leaf tissue pigment in non-treated and abscisic acid (ABA) treated 'MicroTina' tomato plants grown in hydroponic nutrient solution. ${ }^{\mathrm{z}}$

\begin{tabular}{lccc}
\hline \multicolumn{4}{c}{ Mean chlorophyll concn $(\mathrm{mg} / 100 \mathrm{~g}$ fresh wt) } \\
\hline ABA $\left(\mathrm{mg} \cdot \mathrm{L}^{-1}\right)$ & Chl $a$ & Chl $b$ & Total Chl \\
\hline 0.0 & 75.71 & 40.78 & 116.49 \\
0.5 & 124.81 & 54.21 & 179.03 \\
5.0 & 128.04 & 57.22 & 185.27 \\
10.0 & 128.21 & 56.24 & 184.45 \\
Contrast & & & \\
Control vs. ABA & $* * *$ & $* * *$ & $* * *$
\end{tabular}

${ }^{\mathrm{z}}$ Mean separation of the ABA treatments were not significant; therefore, ABA treatments were pooled for statistical analysis.

${ }^{\mathrm{y}} \mathrm{Chl} a=$ chlorophyll $a$; Chl $b=$ chlorophyll $b$; Total $\mathrm{Chl}=$ total chlorophyll. SE was Chl $a \pm 11.94$, Chl $b \pm 3.09$, Total Chl \pm 14.57 . x*** Significant at $P \leq 0.001$.

and chlorophyll pigments compared with the control treatments with no ABA.

IMPACT OF ABA ON TOMATO FRUIT CAROTENOIDS. In 'MicroTina' tomato fruit, there was an increase in LYCO concentrations by $35.5 \%$ when comparing ABA treatments concentrations with the control treatment with $0.0 \mathrm{mg} \cdot \mathrm{L}^{-1}$ of ABA (Table 5). In contrast, there were no significant differences in 'MicroGold' fruit tissue carotenoids. This may be the result of the low concentrations of BC in 'MicroGold' tomato fruit tissue (Table 6). Additionally, LYCO concentrations in 'MicroGold' tomato fruit tissue were below the detection limit of the HPLC (Table 6). Thus, LYCO could not be measured accurately.

\section{Discussion}

Applications of exogenous ABA increased concentrations of tomato leaf carotenoids such as ZEA, BC, LUT, and NEO. Thus, ABA may indirectly regulate the carotenoid pathway by increasing the activity of key enzymes such as BC hydroxylase and phytoene synthase (PSY) (Meier et al., 2011). Under stress conditions such as drought or high salinity, ABA increases, creating a stress response in the plant. The increased activities 
Table 4. Mean values for chlorophyll leaf tissue pigment in non-treated and abscisic acid (ABA) treated 'MicroGold' tomato plants grown in hydroponic nutrient solution. ${ }^{\mathrm{z}}$

\begin{tabular}{lccc}
\hline \multicolumn{4}{c}{ Mean chlorophyll concn $(\mathrm{mg} / 100 \mathrm{~g}$ fresh wt) } \\
\hline ABA $\left(\mathrm{mg} \cdot \mathrm{L}^{-1}\right)$ & Chl $a$ & Chl $b$ & Total Chl \\
\hline 0.0 & 86.43 & 43.90 & 130.33 \\
0.5 & 142.24 & 57.34 & 199.57 \\
5.0 & 144.50 & 58.89 & 203.39 \\
10.0 & 138.40 & 59.18 & 197.58 \\
Contrast & & & \\
Control vs. ABA & $* * *$ & $* * *$ & $* * *$
\end{tabular}

${ }^{\mathrm{z}}$ Mean separation of the ABA treatments were not significant; therefore, ABA treatments were pooled for statistical analysis.

${ }^{\mathrm{y}} \mathrm{Chl} a=$ chlorophyll $a$; Chl $b=$ chlorophyll $b$; Total $\mathrm{Chl}=$ total chlorophyll. SE was Chl $a \pm 10.26$, Chl $b \pm 2.48$, Total Chl \pm 12.51 .

${ }^{x}$ Significant at $P \leq 0.001$.

Table 5. Mean values for carotenoids fruit tissue pigment in nontreated and abscisic acid (ABA) treated 'MicroTina' tomato plants grown in hydroponic nutrient solution. ${ }^{\mathrm{z}}$

\begin{tabular}{lclc}
\hline \multicolumn{4}{c}{ Mean carotenoid concn $(\mathrm{mg} / 100 \mathrm{~g} \text { fresh } \mathrm{wt})^{\mathrm{y}}$} \\
\hline $\mathrm{ABA}\left(\mathrm{mg} \cdot \mathrm{L}^{-1}\right)$ & $\mathrm{BC}$ & LUT & LYCO \\
\hline 0.0 & 0.189 & 0.164 & 2.530 \\
0.5 & 0.230 & 0.164 & 3.908 \\
5.0 & 0.213 & 0.178 & 3.281 \\
10.0 & 0.281 & 0.223 & 4.570 \\
Contrast & & &
\end{tabular}

Control vs. ABA $^{\mathrm{x}}$

NS

NS

NS

${ }^{\mathrm{z}}$ Mean separation of the ABA treatments were not significant; therefore, $\mathrm{ABA}$ treatments were pooled for statistical analysis.

${ }^{\mathrm{y}} \mathrm{BC}=\beta$-carotene; LUT $=$ lutein; $\mathrm{LYCO}=$ lycopene. $\mathrm{SE}$ was $\mathrm{BC} \pm$ $0.105, \mathrm{LUT} \pm 0.076, \mathrm{LYCO} \pm 0.631$.

${ }^{\mathrm{N} S}$ indicates nonsignificant at $P \leq 0.05$.

Table 6. Mean values for carotenoids fruit tissue pigment in nontreated and abscisic acid (ABA) treated 'MicroGold' tomato plants grown in hydroponic nutrient solution. ${ }^{\mathrm{z}}$

\begin{tabular}{lccc}
\hline & \multicolumn{3}{c}{ Mean carotenoid concn $(\mathrm{mg} / 100 \mathrm{~g} \text { fresh wt })^{\mathrm{y}}$} \\
\cline { 2 - 4 } ABA $\left(\mathrm{mg} \cdot \mathrm{L}^{-1}\right)$ & $\mathrm{BC}$ & LUT & LYCO \\
\hline 0.0 & 0.016 & 0.176 & $\mathrm{BDL}^{\mathrm{x}}$ \\
0.5 & 0.017 & 0.093 & $\mathrm{BDL}$ \\
5.0 & 0.007 & 0.131 & $\mathrm{BDL}$ \\
10.0 & 0.012 & 0.134 & $\mathrm{BDL}$
\end{tabular}

Contrast

Control vs. $\mathrm{ABA}^{\mathrm{w}}$ NS NS NA

${ }^{\mathrm{z}}$ Mean separation of the ABA treatments were not significant; therefore, $\mathrm{ABA}$ treatments were pooled for statistical analysis.

${ }^{\mathrm{y}} \mathrm{BC}=\beta$-carotene; LUT $=1$ lutein; $\mathrm{LYCO}=1$ lycopene. $\mathrm{SE}$ was $\mathrm{BC} \pm$ $0.004, \mathrm{LUT} \pm 0.047$.

${ }^{\mathrm{x}}$ Below detection limit.

${ }^{w_{N S}}$ indicates nonsignificant at $P \leq 0.05$.

$\mathrm{NA}=$ not available.

of these enzymes require an available source of isoprenoid substrates, which leads to the production of carotenoids. Previous research has demonstrated that abiotic stress-induced ABA formation leads to the positive regulation of PSY3 gene expression. The positive regulation increases PSY activity feeding carotenoids into the pathway for production of ABA (Welsch et al., 2008). In arabidopsis (Arabidopsis thaliana) seedlings, elevated expression of PSY resulted in increased carotenoid levels (Rodriguez-Villalon et al., 2009). In addition, Du et al. (2010) found that activity of BC hydroxylases from rice (Oryza sativa), which was shown to be a rate-limiting step for ABA biosynthesis, can alter the plant resistance to drought and oxidative stress by modulating the levels of xanthophylls and ABA synthesis.

This study also found that application of ABA increased Chl $a$ and $\mathrm{Chl} b$ levels in the tomato leaf tissue. These findings are logical because carotenoids and chlorophylls are derived from the 2-C-methyl-D-erythritol 4-phosphate (MEP) pathway. Because both carotenoids and chlorophylls are derived from the MEP pathway, ABA may act similarly by increasing the levels of both in leaf tissue. These findings are consistent with previous studies. Pospisilova et al. (1993) found that chlorophylls $(a+b)$ and BC concentrations were higher in ABA-treated tobacco plantlets. In addition, applications of ABA to barley seedlings increased total carotenoids, thus protecting PSII against photoinhibition (Ivanov et al., 1995). Previous research has demonstrated that increases in carotenoid pools reduce plant sensitivity to adverse environmental stress conditions ( $\mathrm{Li}$ et al., 2008). For example, carotenoids are considered to be the main singlet oxygen quenchers in chloroplasts and protect chlorophylls from oxidative damage. Ramel et al. (2012a) found that the accumulation of different volatile derivatives of BC such as $\beta$-cyclocitral caused a photo-oxidative stress signal that induced changes in the expression of a large set of genes identified as singlet oxygen-responsive genes. In another study, BC endoperoxide rapidly accumulated during high-light stress, which was correlated with the extent of PSII photoinhibition and the expression of various singlet oxygen marker genes (Ramel et al., 2012b).

These studies support the idea that increased levels of chlorophylls and carotenoids in the leaf tissue, induced by ABA treatments, can increase the antioxidant capacity of plants to abiotic-induced stress. It may be possible to use ABA as a viable and novel approach to increase plant capacity to combat abiotic-induced stress by increasing leaf carotenoids such as ZEA and BC, allowing for a better response to abiotic stress. These results pose questions regarding why the application of ABA increased some carotenoids and not others. The current study did not answer these questions. Therefore, other research may be needed to identify plausible solutions.

ABA treatments had a significant effect on LYCO concentrations in 'MicroTina' tomato fruit tissue. There was also an increase in fruit BC concentrations. Therefore, ABA demonstrated a positive impact on tomato fruit carotenoids for this genotype. However, ABA treatments had no significant impact on 'MicroGold' fruit carotenoid concentrations. The lack of influence of ABA on 'MicroGold' fruit carotenoids may be the result of the very low concentrations of pigments present in the fruit tissues of this genotype. Research had demonstrated the genetic makeup of tomato cultivars determines the concentrations of metabolites in tomato. However, environmental factors also strongly affect the concentrations of metabolites (Brandt et al., 2012; Helyes et al., 2007). Thus, the impact of ABA on tomato fruit carotenoids may be from the triggering of ethylene biosynthesis that usually results from higher concentrations of ABA. Previous research from Buta and Spaulding (1994) found that the highest levels of tomato fruit ABA occurred at the pink stage $(40 \mathrm{~d})$, followed by a significant decline during subsequent ripening stages. They demonstrated that as the fruit ripened, 
ethylene concentrations increased, whereas ABA levels decreased, which may lead to an increase in carotenoid production in the ripening fruit tissue. Other studies have also demonstrated that decreases in endogenous ABA resulted in increases of carotenoid concentrations. Decreases in ABA led to increases in ethylene production by increasing transcription of genes related to the synthesis of ethylene during tomato fruit ripening (Sun et al., 2012). Therefore, ABA's most important function is in the pre-ripening stage of fruit tissues, when it triggers ethylene production causing an increase in carotenoid production.

This study demonstrated the positive impacts of root tissue ABA applications on tomato leaf pigmentation and fruit tissue carotenoid concentrations. The results showed that ABA increased tomato leaf chlorophylls and carotenoids, and increased tomato fruit LYCO. This means that ABA could potentially regulate carotenoid composition during ripening and may control ethylene production in tomato fruit. One of the implications of this study is that ABA has a positive effect on tomato carotenoids and chlorophylls in the leaf tissue. Increase in carotenoids and chlorophylls in the leaf tissue may improve its antioxidant capacity, thus giving protection to the photosynthetic apparatus under adverse abiotic stress conditions. In addition, the improved antioxidant capacity increases the nutritional value of the tomato fruit. Thus, the benefits of ABA as a powerful tool may only be feasible by protecting the plant from oxidative stress factors and increasing nutritional values in the fruit.

\section{Literature Cited}

Berli, F.J., D. Moreno, P. Piccoli, L. Hespanhol-Viana, M.F. Silva, R. Bressan-Smith, J.B. Cavagnaro, and R. Bottini. 2010. Abscisic acid is involved in the response of grape (Vitis vinifera L.) cv. Malbec leaf tissues to ultraviolet-B radiation by enhancing ultraviolet-absorbing compounds, antioxidant enzymes and membrane sterols. Plant Cell Environ. 33:1-10.

Brandt, B., D.E. Brodsky, S.W. Xue, J. Negi, K. Iba, J. Kangasjarvi, M. Ghassemain, A.B. Stephan, H.H. Hu, and J.I. Schroeder. 2012. Reconstitution of abscisic acid activation of SLAC1 anion channel by CPK6 and OST1 kinases and branched ABI1 PP2C phosphatase action. Proc. Natl. Acad. Sci. USA 26:10593-10598.

Buta, J.G. and D.W. Spaulding. 1994. Changes in indole-3-acetic acid and abscisic acid levels during tomato (Lycopersicon esculentum Mill) fruit development and ripening. J. Plant Growth Regul. 13:163166.

Cantin, C.M., M.W. Fidelibus, and C.H. Crisostoc. 2007. Application of abscisic acid (ABA) at veraison advanced red color development and maintained postharvest quality of 'Crimson Seedless' grapes. Postharvest Biol. Technol. 46:237-241.

Desikan, R., M.K. Cheung, A. Clarke, S. Golding, M. Sagi, R. Fluhr, C. Rock, J. Hancock, and S. Neill. 2004. Hydrogen peroxide is a common signal for darkness- and ABA-induced stomatal closure in Pisum sativum. Funct. Plant Biol. 31:913-920.

Du, H., N.L. Wang, F. Cui, X.H. Li, J.H. Xiao, and L.Z. Xiong. 2010. Characterization of the beta-carotene hydroxylase gene DSM2 conferring drought and oxidative stress resistance by increasing xanthophylls and abscisic acid synthesis in rice. Plant Physiol. 154:1304-1318.

Emenhiser, C., N. Simunovic, L.C. Sander, and S.J. Schwartz. 1996. Separation of geometric carotenoid isomers in biological extracts using a polymeric $\mathrm{C}_{30}$ column in reverse-phase liquid chromatography. J. Agr. Food Chem. 44:3887-3893.

Garcia-Mina, J.M., E. Bacaicoa, M. Fuentes, and E. Casanova. 2013. Fine regulation of leaf iron use efficiency and iron root uptake under limited iron bioavailability. Plant Sci. 198:39-45.

Haisel, D., J. Pospisilova, H. Synkova, R. Schnablova, and P. Batkova. 2006. Effects of abscisic acid or benzyladenine on pigment contents, chlorophyll fluorescence, and chloroplast ultrastructure during water stress and after rehydration. Photosynthesis 44:606-614.

Helyes, L., A. Lugasi, and Z. Pek. 2007. Effect of natural light on surface temperature and lycopene content of vine ripened tomato fruit. Can. J. Plant Sci. 4:927-929.

Ivanov, A.G., M. Krol, D. Maxwell, and N.P.A. Huner. 1995. Abscisicacid induced protection against photoinhibition of PSII correlates with enhanced activity of the xanthophyll cycle. FEBS Lett. 371:61-64.

Jiang, M.Y. and J.H. Zhang. 2002. Water stress-induced abscisic acid accumulation triggers the increased generation of reactive oxygen species and up-regulates the activities of antioxidant enzymes in maize leaves. J. Expt. Bot. 379:2401-2410.

Khachik, F., G.R. Beecher, and N.F. Whittaker. 1986. Separation, identification, and quantification of the major carotenoids and chlorophyll constituents in extracts of several green vegetables by liquidchromatography. J. Agr. Food Chem. 34:603-616.

Kopsell, D.A., D.E. Kopsell, and J. Curran-Celentano. 2007. Carotenoid pigments in kale are influenced by nitrogen concentration and form. J. Sci. Food Agr. 87:900-907.

Kopsell, D.A., D.E. Kopsell, M.G. Lefsrud, J. Curran-Celentano, and L.E. Dukach. 2004. Variation in lutein, beta-carotene, and chlorophyll concentrations among Brassica oleracea cultigens and seasons. HortScience 39:361-364.

Li, F.Q., R. Vallabhaneni, and E.T. Wurtzel. 2008. PSY3, a new member of the phytoene synthase gene family conserved in the poaceae and regulator of abiotic stress-induced root carotenogenesis. Plant Physiol. 146:1333-1345.

Liu, J.Q., D.L. Allan, and C.P. Vance. 2010. Systemic signaling and local sensing of phosphate in common bean: Cross-talk between photosynthate and MicroRNA399. Mol. Plant 3:428-437.

Meier, S., O. Tzfadia, R. Vallabhaneni, C. Gehring, and E.T. Wurtzel. 2011. A transcriptional analysis of carotenoid, chlorophyll and plastidial isoprenoid biosynthesis genes during development and osmotic stress responses in Arabidopsis thaliana. BMC Syst. Biol. 5:77-96.

Miller, N.J., J. Sampson, L.P. Candeias, P.M. Bramley, and C.A. RiceEvens. 1996. Antioxidant activities of carotenes and xanthophylls. FEBS Lett. 3:240-242.

Pék, Z., L. Helyes, and A. Lugasi. 2010. Color changes and antioxidant content of vine and postharvest-ripened tomato fruit. HortScience 3:466-468.

Pospisilova, J., J. Catsky, H. Synkova, I. Machackova, and J. Solarova. 1993. Gas-exchange and in-vivo chlorophyll fluorescence in potato and tobacco plantlets in-vitro as affected by various concentrations of 6-benzylaminopurine. Photosynthesis 29:1-12.

Ramel, F., S. Birtic, C. Ginies, L. Soubigou-Taconnat, C. Triantaphylides, and M. Havaux. 2012a. Carotenoid oxidation products are stress signals that mediate gene responses to singlet oxygen in plants. Proc. Natl. Acad. Sci. USA 109:5535-5540.

Ramel, F., S. Birtic, S. Cuine, C. Triantaphylides, J.L. Ravanat, and M. Havaux. 2012b. Chemical quenching of singlet oxygen by carotenoids in plants. Plant Physiol. 158:1267-1278.

Rodriguez-Villalon, A., E. Gas, and M. Rodriguez-Concepcion. 2009. Phytoene synthase activity controls the biosynthesis of carotenoids and the supply of their metabolic precursors in dark-grown Arabidopsis seedlings. Plant J. 60:424-435.

Sharma, P.K., S. Sankhalkar, and Y. Fernandes. 2002. Possible function of $\mathrm{ABA}$ in protection against photodamage by stimulating xanthophyll cycle in sorghum seedlings. Curr. Sci. 82:167-171.

Sun, L., B. Yuan, M. Zhang, L. Wang, M.M. Cui, Q. Wang, and P. Leng. 2012. Fruit-specific RNAi-mediated suppression of SINCED1 increases both lycopene and beta-carotene contents in tomato fruit. J. Expt. Bot. 63:3097-3108.

Tang, L.L., T.Y. Jin, X.B. Zeng, and J.S. Wang. 2005. Lycopene inhibits the growth of human androgen-independent prostate cancers cells in-vitro and in BALB/c nude mice. J. Nutr. 2:287-290.

Taylor, I.B., R.S.T. Linforth, R.J. Alnaieb, W.R. Bowman, and B.A. Marples. 1988. The wilty tomato mutants flacca and sitiens are 
impaired in the oxidation of ABA-aldehyde to ABA. Plant Cell Environ. 11:739-745.

Wang, W.H., X.Q. Yi, A.D. Han, T.W. Liu, J. Chen, F.H. Wu, X.J. Dong, J.X. He, Z.M. Pei, and H.L. Zheng. 2012. Calcium-sensing receptor regulates stomatal closure through hydrogen peroxide and nitric oxide in response to extracellular calcium in Arabidopsis. J. Expt. Bot. 63:177-190.

Welsch, R., F. Wust, C. Bar, S. Al-Babili, and P. Beyer. 2008. A third phytoene synthase is devoted to abiotic stress-induced abscisic acid formation in rice and defines functional diversification of phytoene synthase genes. Plant Physiol. 147:367-380.

Zaharah, S.S., Z. Singh, G.M. Symons, and J.B. Reid. 2013. Mode of action of abscisic acid in triggering ethylene biosynthesis and softening during ripening in mango fruit. Postharvest Biol. Technol. 75:37-44.

Zhang, M., B. Yuan, and P. Leng. 2009. The role of ABA in triggering ethylene biosynthesis and ripening of tomato fruit. J. Expt. Bot. 60:1579-1588. 